Annette Paatz

\title{
Literatura "(latino-/hispano-/sud-)americana" en el siglo XIX: la perspectiva continental
}

La literatura latinoamericana del siglo XIX ha sido considerada principalmente como proyecto fundacional y, por lo tanto, nacional. Un primer paso hacia el registro de la producción literaria del momento se dio con las antologías, verdaderos puntos de partida para la construcción de un patrimonio literario. Hugo Achugar las analizó en el ámbito de los distintos estados nacionales, y les atribuyó el significativo término de "parnasos fundacionales" (Achugar 1997: 20).

Después de estas recopilaciones antológicas, las historias literarias supondrían un segundo paso en el proyecto literario fundacional. Ellas intentan añadirle a la creación actual una perspectiva histórica según determinados criterios de ordenación. En la historiografía literaria, la perspectiva nacional imperó todavía más, muy acorde con las pautas historiográficas románticas de buscar las particularidades del "espíritu nacional" que emana de las condiciones específicas de un determinado momento y un determinado lugar. Beatriz GonzálezStephan destaca por ejemplo para el siglo XIX una "modalidad nacional en detrimento de la continental americanista" (González-Stephan 2002: 215). Sin embargo, al examinar más detenidamente los proyectos antológicos que preceden a la historiografía literaria propiamente dicha, se puede observar paralelamente una tendencia que resume la producción literaria de distintos países bajo un marco común pan-latinoamericano. De este modo, cabe suponer que a pesar de la predominancia del registro nacional, coexisten con éste empeños más generales que apuntan hacia una literatura "americana" (GonzálezStephan 2002: 212): "Ambas percepciones -local/continental- coexistieron", concluye González-Stephan, "con diversos énfasis de acuerdo con intereses y coyunturas" (González-Stephan 2002: 216).

Ahora bien, esta perspectiva continental se debe muchas veces a cuestiones de punto de vista: importa desde dónde y para quien se escribe. Hay que considerar las antologías como elementos de la prác- 
tica literaria del momento, dentro de sus respectivas circunstancias de producción y recepción. Entonces se revela que las denominaciones elegidas para el producto a presentar, sea "latino-", "hispano-", "sud-" o simplemente "americano", responden tanto a las condiciones materiales del proceso cultural como a factores ideológicos claramente perceptibles. Es lo que procuro demostrar a lo largo de las presentes consideraciones.

Las primeras antologías literarias aparecen en Hispanoamérica ya en los primeros años de la Independencia, para llegar a una verdadera ola de publicación a partir de mediados del siglo XIX. Esta preocupación por recopilar la producción literaria del subcontinente desembocó finalmente en la publicación de obras de historiografía literaria nacionales, con un destacado auge hacia finales del siglo y llegando hasta las primeras décadas del siglo XX. Tanto antologías como historias literarias funcionaban entonces como actos fundacionales, lugares de memoria, originarios del patrimonio cultural. Pero cuando las historias literarias buscaron una tradición literaria, un origen de la literatura nacional en tiempos anteriores en las antologías que las preceden, destacó lo que Roberto González Echevarría ha llamado su "presentismo": "Resulta claro que una de las ideas implícitas en estos libros es que la literatura latinoamericana empieza con la ruptura política y el nacimiento de las naciones libres" (González Echevarría 1994: 497). Esta inmediatez presentaba efectivamente el punto con el cual se pudo lograr más claramente un distanciamiento de la carga histórica de la España colonizadora.

Se trataba de marcar la base de un legado cultural para cubrir un vacío. Aun cuando se encontraban en ocasiones otras propuestas que situaban el comienzo de la literatura hispanoamericana en distintos momentos históricos anteriores a la Independencia, imperaba bastante esta idea de una literatura emergente, por crear, lo que llevaba a una curiosa simultaneidad: en el momento de desarrollarse la literatura, ya formaba parte del patrimonio cultural. Por consiguiente, el trabajo recopilador tenía la finalidad de crear un "monumento poético", como se dice una vez en la antología América poética de José Domingo Cortés, un autor sumamente productivo en este tipo de proyectos (Cortés 1875: s.p.). Surgieron álbumes, ramilletes, parnasos, liras, o, en los términos de Andrés Bello, "bibliotecas" y "repertorios" americanos. De hecho, la Biblioteca americana y el Repertorio ameri- 
cano de Bello no son antologías propiamente dicho sino publicaciones periodísticas, pero contienen asimismo obras de creación, como por ejemplo las conocidas Silvas americanas del mismo Bello. Resalta así desde el primer momento una estrecha interrelación entre literatura y periodismo sobre la que habrá que volver. En general, las colecciones antológicas se publicaban o bien en ediciones individuales o bien en forma de entregas sueltas sujetas a la suscripción: formar una literatura, en no poca medida, implicaba al mismo tiempo formar a un público.

En esta dinámica el contemporáneo desarrollo de la crítica literaria influyó de manera sustancial, ya que nos encontramos precisamente en el momento cuando empieza a institucionalizarse la crítica literaria tanto en Europa como, en menor medida, en América Latina. El proceso estaba relacionado inseparablemente con las condiciones mediáticas y sobre todo con un nuevo formato periodístico, a saber, la revista cultural, cuyo mayor exponente fue la francesa Revue des Deux Mondes, que empieza a circular a partir de 1830. Es el momento cuando tanto la creación literaria como la crítica de la misma experimentan una presencia mediática no conocida antes, y es también el momento cuando los lectores de los periódicos definitivamente ya no se limitan a las elites eruditas sino que incluyen -por lo menos teóricamente- a unas comunidades lectoras mucho más amplias. Precisamente para sociedades no tan adelantadas en la industria editorial, las revistas brindan una manera de llevar a cabo el proceso de formar la idea de un conjunto de una producción literaria nacional o continental. Son muy frecuentes los apartados de "literatura americana" en las más diversas publicaciones periódicas, lo que llevó a Boyd C. Carter a proponer de pensar la Historia de la literatura hispanoamericana a través de sus revistas (1968).

Las mencionadas actividades no se desarrollaron en un campo cultural autónomo, sino que eran la expresión de una voluntad a la vez literaria y política. Según Achugar, "[e]l sujeto interpelado por los parnasos fundacionales de nuestra América es el ciudadano" (Achugar 1997: 20). Al hablar de los comienzos de la literatura (latino-/hispano/sud-)americana hay que tener en cuenta esta situación específica: estamos ante una destacada funcionalización política del quehacer literario, el cual se demuestra todavía muy centrado en los autores, y 
ante una actitud prospectiva que instrumentaliza la creación literaria en vista de una proyección hacia el futuro.

Por último, la práctica literaria procuraba también visualizar hacia afuera la existencia de un conjunto autónomo de textos autóctonos. De ahí que la perspectiva transnacional merezca una atención particular en el presente contexto. Los proyectos antológicos, críticos e historiográficos tuvieron desde sus comienzos una dimensión dialógica, lo que implica también la necesidad de especificar las atribuciones de emisores y receptores a colectivos determinados.

En lo siguiente se van a situar algunas antologías de alcance continental dentro de las circunstancias esbozadas. Indagaré sobre todo en las posibilidades y también límites relacionados con tales proyectos, basándome sobre todo en aquellas antologías que llegan a considerar una cantidad de obras y autores que representan un panorama relativamente completo de la producción literaria latinoamericana: son, básicamente, los Ensayos biográficos y de crítica literaria (París, 1863/1868) de José María Torres Caicedo, la América poética de José Domingo Cortés (París, 1875), y las dos ediciones de la América literaria de Francisco Lagomaggiore (Buenos Aires, 1883/1890).

En los proyectos editoriales analizados, se favorece con frecuencia el adjetivo "americano", lo que ayuda a enfatizar la amplitud del concepto. Sin embargo, la utilización del término responde por lo menos durante algunos períodos a las muchas veces complicadas situaciones políticas con las que se veían enfrentados los autores y editores. Importa sobre todo el lugar de publicación y la consiguiente necesidad de hablar en términos más generales para corresponder al horizonte de los respectivos públicos. De ahí que Juan María Gutiérrez opte por el nombre América poética para su proyecto antológico con textos de autores contemporáneos publicados a lo largo de 1846 y 1847. El proyecto se llevó a cabo en Chile, donde el argentino Gutiérrez había llegado a vivir exiliado como muchos más de sus compatriotas durante el régimen rosista. Esta circunstancia explica la desviación de su atención de la perspectiva nacional hacia un alcance más amplio con el fin de establecer un fondo de textos del que pueda surgir un patrimonio cultural. Tales situaciones transnacionales eran muy frecuentes en aquellos tiempos: al mismo contexto del exilio argentino se debe el hecho de que Bartolomé Mitre, quien poste- 
riormente llegaría a ser el primer presidente de la República Argentina, publicara su novela Soledad (1847) como folletín en el periódico La Época de La Paz, Bolivia. La obra que llegó a considerarse la primera novela argentina, tiene un referente temático boliviano y se volvió a publicar un año más tarde como libro en Valparaíso, Chile. Es muy conocido -seguramente más que la novela misma, de la que el gran hombre de Estado posteriormente renegó- el programático prólogo, en el que el autor precisamente lamenta la escasez de novelas no en su país, sino en toda la "América del Sud" (Mitre 1928: 93). Y en 1907, el chileno Pedro Pablo Figueroa reedita la novela argentina junto con otro texto del mismo Mitre todavía bajo el título genérico Dos perlas literarias americanas. Parece obvio que al cruzar las fronteras nacionales, la denominación "americano" tiene una motivación simplemente pragmática. O bien, en el caso de Mitre, el propio autor opta por el calificativo de "americano" para colocar su obra en un conjunto más abarcador, o bien, en el caso de Figueroa, la obra de un escritor perteneciente a otra nación entra como "americana" en el patrimonio compartido con su editor.

Este tipo de denominación genérica, de "americano" sin especificación ulterior, se sigue observando a lo largo del siglo XIX: una segunda América poética se publica en 1854/56 en La Habana, y el mismo Gutiérrez lanza asimismo una segunda serie América poética en 1865. El chileno José Domingo Cortés publica el tomo Poetas americanos en 1863 y las antologías Poetisas americanas y América poética en 1875. Ricardo Palma presenta una Lira americana en 1872, y también en 1883 y 1890, Francisco Lagomaggiore saca una primera y segunda tirada de su extensa América literaria. Existía obviamente una noción abarcadora del proceso literario que permitía esta visión de un conjunto cultural "americano". ${ }^{1}$

Llama la atención que buena parte de las antologías decimonónicas se publicaron o tuvieron reediciones en editoriales parisinas. De hecho, la capital francesa se prestaba para tales empresas, básicamente por dos razones: por un lado, la infraestructura editorial estaba mucho más avanzada $\mathrm{y}$, segundo, la distribución pan-latinoamericana se veía facilitada por el desarrollo de las vías marítimas hacia el subcon-

1 Recuentos de las antologías tanto nacionales como continentales se encuentran en los ensayos de Campra (1987), González Echevarría (1994) y Achugar (1997). 
tinente latinoamericano desde que habían empezado a funcionar los barcos a vapor. Desde París no se garantizaba sólo una distribución a través del subcontinente entero, sino también la posibilidad de dar a conocer la producción literaria hispanoamericana a nivel mundial.

El fenómeno más llamativo en este sentido fueron seguramente los Ensayos biográficos y de crítica literaria sobre los principales poetas y literatos hispano-americanos (2 tomos, 1863) y un segundo volumen de la misma colección, los Ensayos biográficos y de crítica literaria sobre los principales publicistas, historiadores, poetas y literatos de la América Latina (1868) publicados por José María Torres Caicedo, un periodista y diplomático colombiano, radicado en París. Esta obra muestra el proceso literario ya en una escala avanza$\mathrm{da}$, una especie de segundo paso, en dos sentidos: por un lado, ya no reúne tan sólo la creación literaria, sino que da informaciones sobre algunos autores hispanoamericanos en una dimensión anteriormente desconocida. De este modo, ya apunta al registro crítico de la producción literaria hispanoamericana. Pero los Ensayos de Torres Caicedo son también una reafirmación de la práctica literaria, porque tenían su raíz en los artículos redactados por el mismo autor en el El Correo de Ultramar, una revista que se editó en París en español y que estuvo destinada a la exportación transatlántica. La serie de artículos publicada en El Correo a partir de 1855 se titulaba "Hombres ilustres de la América Española", lo que subraya la importancia de las personalidades que contribuían al proyecto de las literaturas nacionales: el prestigio de los autores era en esos momentos casi más importante que el propio texto literario. ${ }^{2}$ Los Ensayos de Torres Caicedo tuvieron una repercusión extraordinaria tanto en la prensa francesa como en la hispanoamericana. ${ }^{3}$ Esta publicación se adelanta a la ola de historias literarias nacionales y autóctonas. Se puede tomar como un pri-

2 Esta observación sigue vigente para las primeras historias literarias: "[U]no de los criterios básicos para determinar el corpus literario es el autor de las obras impresas, independientemente de la materia tratada. Es decir, el hombre productor de escritos literarios, de conocimientos varios, de poesía, de historia, gramática, leyes. Pudiéramos afirmar que el criterio regulador para la catalogación fue la autoria" (González-Stephan 2002: 244).

3 He trabajado sobre la recepción francesa de la obra en mi ensayo "Paris et les débuts de l'histoire littéraire hispano-américaine" que está por publicarse en las actas del coloquio "Histoire, mémoire, littérature", editadas por Franziska Meier et al. en Presses Universitaires de Caen. 
mer intento hacia un inventario crítico continental de la literatura hispanoamericana. Así lo constata también Alfred Coester al publicar su propia historia de la literatura hispanoamericana -la primera de alcance continental- en 1916:

J.M. Torres Caicedo deserves the praise and thanks of everybody interested in Spanish-American Literature. His Ensayos biográficos y de Critica literaria [...] was the first attempt to treat the whole field and is still invaluable (Coester 1916: 303).

Torres Caicedo adopta una perspectiva eurocéntrica al hablar, en el prólogo que escribe al comenzar la serie de retratos en 1855, de América Latina como "virgen del mundo":

La América ${ }^{(1)}$, esa vírgen del mundo, como la ha apellidado Quintana, no llama la atencion en Europa, sino por las luchas constantes que la agi$\tan .[\ldots]$

${ }^{(1)}$ Hablamos de la América española, ó latina (Torres Caicedo 1863, I: 1).

Este mismo prólogo se incluye asimismo en el primer tomo de los Ensayos de 1863, y me parece llamativo y debido a la parte francesa de su público lector que, en nota a pie de página, puntualice que su América comprende la parte española, respectivamente latina.

La selección comprende casi exclusivamente autores contemporáneos, como era común y corriente en la época. En este sentido, el proyecto de Torres Caicedo coincide en cuanto a su proximidad temporal con las antologías de creación. En ese mismo prólogo de 1855 subraya el espíritu de improvisación que caracteriza su labor:

$[\mathrm{H}]$ oy, desprovistos de documentos y materiales, cediendo á las instancias de varios amigos nuestros, pensamos dar alguna ligera idea acerca de la vida y los escritos de algunos de los literatos y estadistas de la América española. [...] No nos anima pretension de ninguna especie; y no pensamos en trazar ni noticias biográficas completas, para lo cual nos faltan datos, ni formar juicios críticos, para lo cual ademas de faltarnos las principales obras de los autores á que nos referimos, nos consideramos escasos de talento y de luces. Solo queremos llamar la atencion sobre algunos de esos hombres dignos de todo elogio, que, en medio de las tempestades que agitan la existencia de esos pueblos nacientes, han consagrado sus dias á la ejecucion de alguna obra útil ó agradable (Torres Caicedo 1863, I: 8).

Estas palabras reflejan la particularidad del discurso literario decimonónico que incluye tanto a "literatos" como "estadistas": la interacción entre política y literatura resulta primordial. Ante semejante acumulación de representantes de la elite política y cultural, Torres Cai- 
cedo procura abstenerse de juicios críticos, simplemente quiere dar a conocer en vez de juzgar, llenar el vacío, demostrar que existen hombres (y alguna mujer) que escriben, que existe una literatura hispanoamericana. Así, su trabajo afirma que los proyectos antológicos decimonónicos quieren reflejar la totalidad del proceso literario en vez de presentar una selección (Campra 1987: 38). Se trataba de dar a conocer a los colectivos criollos en los distintos estados hispanoamericanos, pero de igual modo al extranjero, la existencia de un proyecto literario americano. Como constató Rosalba Campra, "[e]n ese momento, ser americano es un hecho ético, no geográfico. La idea nacional de literatura se ve rebasada por el concepto de americanidad" (Campra 1987: 38).

Los tres tomos que Torres Caicedo llegó a publicar comprenden un total de aproximadamente 1.500 páginas e incluyen, sin ningún orden alfabético obvio o según nacionalidades, a los siguientes autores.

En el primer tomo de la "primera serie" (1863): Salvador Sanfuentes y José Victorino Lastarria de Chile; José María Heredia de Cuba; Rafael María Baralt, Andrés Bello, Abigail Lozano y José Heriberto García de Quevedo de Venezuela - cantidad relativamente extensa que puede deberse al hecho de que Torres Caicedo ejerció en París como ministro plenipotenciario de ese país-; José Joaquín Olmedo de Perú; Silveria Espinosa de Rendón, José Fernández Madrid, José Eusebio Caro y Antonio Calcaño de Colombia -país natal del compilador; Antonio José de Irrisarri de Guatemala; Bartolomé Mitre, Esteban Echeverría, Florencio Balcarce y Claudio Mamerto Cuenca de Argentina; Guillermo Prieto y R.P.Fr. Manuel de Navarrete de México - este último una excepción en el elenco de autores porque murió ya en 1809 .

En el segundo tomo de la "primera serie": Julio Arboleda y Manuel María Madiedo de Colombia; José Mármol e Hilario Ascasubi de Argentina; José Antonio Maitín de Venezuela, Francisco Manuel Sánchez de Tagle, José María Esteva, Ignacio Rodriguez Galván y Joaquín Pesado de México; Guillermo Matta, Guillermo Blest Gana, Eusebio Lillo, Miguel Luis Amunátegui, José Joaquín Vallejo y Hermógenes Irisarri de Chile; Juan Carlos Gómez de Uruguay; Gabriel de la Concepción Valdés de Cuba; Manuel Nicolás Corpancho de Perú. 
En el segundo volumen de 1868 se puede observar una clara predominancia de autores argentinos: María [sic] Manuela Gorriti, Juan María Gutiérrez, Florencio Varela, Juan Crisóstomo Lafinur, José Rivera Indarte, Vicente G. Quesada, Juan Bautista Alberdi y Luis L. Domínguez. Luego constan Alejandro Magarinos Cervantes, Francisco Acuña de Figueroa y Heraclio C. Fajardo de Uruguay; Antonio Flores y Juan León Mera de Ecuador; José Ramón Yepes de Venezuela; Ricardo Palma de Perú; Lázaro María Pérez Cartagena, Julián de Torres y Peña y José M. Groot Florentino González de Colombia.

Con los trabajos de Torres Caicedo se pasa de la adjetivación "americano" a denominaciones más específicas. Es obvio que desde París, el lugar de la publicación, la expresión genérica "americano" se identifica con los Estados Unidos, por lo que se precisa una puntualización. Pero se puede observar también un desarrollo muy llamativo al considerar los distintos términos utilizados por Torres Caicedo a lo largo de la historia editorial de sus ensayos: al iniciar su colección en El Correo de Ultramar en 1855, habla todavía de la "América Española". Con los dos tomos de 1863 cambia a "hispano-americano", eliminando de este modo la vinculación colonial. En el título de 1868, "hispano-americano" es sustituido, finalmente, por "de la América Latina". Esta opción por el adjetivo "latino" seguramente no se efectuó por casualidad, sino que apunta al hecho de que detrás del compromiso de Torres Caicedo para con la literatura de los países hispanoamericanos se encuentran destacados intereses políticos: lo literario y lo político se ven nuevamente reunidos, incluso en la práctica discursiva concreta de Torres Caicedo. El escritor era un ferviente defensor de un programa político de "unión latino-americana" y autor de unos cuantos tratados al respecto. ${ }^{4}$

Por otro lado, cabe destacar que en estos momentos en Francia, el concepto de la latinité empezaba a llegar a su punto culminante como justificación de la política de expansión napoleónica. La idea de la solidaridad de una "raza latina" estaba en el aire, y se puede suponer

4 El escrito más importante lleva el impresionante título Unión latino-americana: pensamiento de Bolivar para formar una liga americana; su origen y sus desarrollos y estudio sobre la gran cuestión que tanto interesa a los estados débiles, a saber: ¿Un gobierno es responsable por los daños y perjuicios ocasionados a los extranjeros por las facciones? (París, 1865). 
que los latinoamericanos que llegaron a París supieron aprovechar este registro. El concepto coadyuvaba a una mayor consideración por parte de Francia, también en un gesto de distanciamiento hacia los cada vez más influyentes Estados Unidos. En este contexto hay que valorar las palabras dedicatorias de un Lamartine, que Torres Caicedo se apresura a incluir en su obra:

$\mathrm{Vd}$. sabe que yo tengo una predileccion marcada por el genio social y poético de sus conciudadanos. Los americanos del Norte no han llevado al Nuevo Mundo sino la civilizacion materialista, fria como el egoismo, ávida como el lucro, prosáica como el mercantilismo anglo-sajon: Vds. han llevado las virtudes y los gustos elevados de la raza latina.

Hago muy frecuentes votos porque cesen las divisiones de esas repúblicas, para que Vds. lleguen á ser lo que merecen: - la gran colonia europea de la civilizacion espiritualista, bajo el bello sol que les alumbra y les inspira (Torres Caicedo 1863, I: s.p.).

Ahora bien, hay que tener en cuenta que las ideas acerca de la latinité y del concepto de lo "latino-americano" defendido por Torres Caicedo tienen sus puntos en común, pero que, por otro lado, no se corresponden por completo. Torres Caicedo quería poner de relieve la novedad de su idea de una unión de las repúblicas del subcontinente. En palabras de Emilio Carilla:

No cabe duda de que al defender sus denominaciones, lo que Torres Caicedo pretendía no era tanto incluir otros sectores "latinos" (como hacían los franceses), sino diluir, o hacer más vagos, nombres tradicionales que evocaban signos de dependencia política. Evidentemente, para Torres Caicedo el nombre Latino América significa sobre todo una nueva entidad política que, sin desconocer antiguos lazos, aspiraba a borrar, con mayor o menor justificación, lo que las denominaciones tradicionales evocan históricamente (Carilla 1990: 65). ${ }^{5}$

5 No cabe duda de que los libros de Torres Caicedo tuvieron un eco considerable en la prensa, tanto francesa como hispanoamericana. Con respecto a Francia, pero también en términos de difusión transatlántica, resulta particularmente importante el artículo largo que salió en febrero de 1864 en la Revue des Deux Mondes. Se trata de un ensayo de casi 30 páginas titulado "La poésie et les poètes dans l'Amérique espagnole", un resumen bastante elogioso de la obra, y el único artículo publicado expresamente sobre literatura hispanoamericana a lo largo de todo el siglo XIX en este importante órgano que ya en su título apuntaba hacia una visión integradora de "ambos mundos". Seguramente sirvió a aumentar de manera bastante considerable el capital simbólico de las letras hispanoamericanas, aun cuando el autor del ensayo, Elisée Reclus, no se destacaba precisamente como experta en crítica literaria. Se trataba más bien de un activista afiliado al movimiento anarquista que como geógrafo había viajado por Latino- 
Los Ensayos de Torres Caicedo fueron recibidos con mucho agrado en el subcontinente latinoamericano, precisamente por llegar a dar simplemente una primera visión de conjunto del proceso literario hispanoamericano. A Vicente Quesada, al reseñar los dos primeros tomos de 1863 en su Revista de Buenos Aires, no le queda duda de que "esta obra debe encontrarse en toda biblioteca americana" (Quesada 1864: 145). Nótese aquí otra vez la denominación global "americana" que sólo se puede utilizar desde una perspectiva subcontinental. Quesada valora el trabajo de Torres Caicedo en el amplio margen de "una noble aspiracion á la unificacion de la literatura americana" (Quesada 1864: 154) y lo ve como un paso importante en "el camino que debemos seguir para formar bibliotecas americanas" (Quesada 1864: 149). Otra vez se expresa la actitud prospectiva de todos esos proyectos, el ir hacia una finalidad bien concreta a pesar de todos los obstáculos que están bien presentes y visibles.

Además, Quesada le concede a la obra un peso todavía mayor en vista de las condiciones particulares de la actividad cultural en América Latina, refiriéndose al desequilibrio de información que existe entre el subcontinente y Europa. Subraya que

[...] esos escritores [europeos, A.P.] no han podido [...] alcanzar la influencia que esa obra debe ejercer en América, porque no conocen el vacio que ha venido á llenar: europeos, están acostumbrados á la fácil comunicacion que los pone al corriente de todos los progresos, de todos los adelantos, mientras que en América sucede lo contrario, sobre todo, tratándose de libros americanos. Lo caro de las impresiones, la dificultad de adquirir esas obras, la carencia casi absoluta del comercio de publicaciones sud-americanas entre los diversos Estados de este continente -ya sea porque las ediciones son poco numerosas, ya porque no existen impresores- editores que especulen en la impresion de los trabajos americanos, ya sea por ese indiferentismo tan fatal sobre todo en las democracias: la verdad es que aquí, no están en venta ediciones de Venezuela á Nueva Granada, por ejemplo, mientras poseemos libros europeos recientemente publicados. ¿Qué resulta de esto pues? La ignorancia del progreso de las letras americanas, el aislamiento intelectual de los escritores demócratas de nuestra raza y de nuestra lengua (Quesada 1864: 147-148).

américa y escrito en la misma Revue sobre estos viajes. Pero sobre todo la coincidencia con Torres Caicedo en el proyecto de una federación hispanoamericana fue lo que motivó en 1866 su artículo "Les Républiques de l'Amérique du Sud. Leurs guerres et leur projet de fédération". El interés de este autor por Hispanoamérica fue entonces más ideológico que literario, lo que, sin embargo, no disminuyó el impacto de su ensayo sobre los méritos literarios de América Latina reunidos en los tomos de Torres Caicedo. Véase al respecto Paatz (2001). 
Parece obvio que el mayor obstáculo para lograr una noción continental de la literatura americana reside en la manifiesta incomunicación entre los distintos centros, y también parece obvio que ésta se hace más evidente con el paso de los años. Son numerosos los comentarios acerca de este tipo de dificultades. Es sumamente interesante en este contexto un intercambio de cartas entre George Ticknor, el autor estadounidense de una History of Spanish Literature, que se publicó en 1849 y cuya traducción española apareció entre 1851 y 1857 , y el argentino Juan María Gutiérrez. Este último, al enterarse de la existencia de esa obra, le había mandado a Ticknor sus Estudios sobre los poetas americanos anteriores al siglo XIX y sus Poesías americanas. Ticknor se lo agradeció mucho, haciendo hincapié en que le hubiera gustado hablar también sobre la literatura hispanoamericana, pero que no le había sido posible por falta de material, sobre todo de los países más alejados:

Ellos [los libros mandados por Gutiérrez, A.P.] son interesantes tributos hechos á la literatura española de este lado del Atlántico, y de la naturaleza de aquellos que se echan menos desde mucho tiempo atrás y cuáles los he buscado en vano repetidas veces.

De Méjico, del Perú y de Cuba, he recibido un número regular de libros, dirijidos directamente por sus mismos autores; pero esta es la vez primera que me llega algo de Buenos Aires. Su envio de vd. es de particular interés para mí, especialmente sus "Estudios", por cuanto tienen noticias que no sabría en qué otro libro encontrar, y una con relacion á Inés de la Cruz, de que me aprovecharé con gusto en la próxima edicion de mi historia de la literatura española ("Correspondencia literaria” 1867: 566).

Vuelve a ser significativo que la denominación genérica utilizada por Gutiérrez se especifique por "literatura española de este lado del atlántico" en la carta de Ticknor. El hispanista estadounidense ya no habla de América, sino que subsume directamente la literatura hispanoamericana a la española. Adopta la misma estrategia que se verá, por lo demás, años más tarde en la Antología de poetas hispanoamericanos de Marcelino Menéndez Pelayo sobre la que habrá que volver: para los investigadores extranjeros, la literatura hispanoamericana sigue formando parte del conjunto de la literatura española y no interesa tanto la pregunta si puede tener sus rasgos distintivos.

El asunto se presenta de manera bastante diferente en una segunda antología denominada América poética que se publica en 1875. La empresa se sitúa en la línea del proyecto pionero de Juan María Gu- 
tiérrez de 1846/47. En esta ocasión, el responsable es el chileno José Domingo Cortés. En el prólogo de dicha obra, dirigido "Á los lectores americanos", alude directamente a la obra antecesora:

La compilacion publicada en Valparaiso en 1846, conocida con el título de AMERICA POÉTICA, muy estimable como obra iniciadora de esta clase de trabajos, y bastante completa para la época en que fué publicada, ha llegado en el dia á ser insuficiente para dar una idea exacta de la altura á que se halla el lirismo en América latina.

En los veintinueve años transcurridos desde la publicacion de aquella obra, el movimiento literario, no solo ha adquirido en las repúblicas hispano-americanas un desarrollo considerable, sino que, principalmente, se ha desembarazado de las trabas de imitacion servil que lo llevaban, por decirlo así, á remolque del movimiento literario europeo, y se ha formado un género propio en armonía con la naturaleza, hábitos y tradicciones [sic] de la América de origen español. Desde la aparicion de aquella recopilacion hasta el dia, muchos poetas desconocidos entónces, y á quienes tal vez no se habia revelado aun la inspiracion, han producido bellísimos cantos y sus nombres ocupan un alto lugar en el parnaso americano.

Los tiernos y afectuosos sentimientos del alma, la naturaleza expléndida [sic] y animada de la Virjen del mundo, los recuerdos de sus primitivas razas y las palpitantes escenas de sus luchas por la independencia y la libertad, han arrancado á las liras americanas ya suaves y dulcísimos sonidos, ya armonías enérjicas y entusiastas, que la Europa ha aplaudido y admirado muchas veces.

Publicaciones como esta, pueden ser miradas favorablemente bajo otro punto de vista; ellas crean en las relaciones literarias la union de nacionalidad que la América busca en sus relaciones sociales, políticas y mercantiles.

Continuar y completar esa historia de las letras americanas, dando á la circulacion sus nuevas y mas notables composiciones, es el objeto de la nueva obra que hoy ofrecemos al público (Cortés 1875: s.p.).

Queda muy obvio en estas palabras que las antologías implican un proyecto historiográfico, $\mathrm{y}$, lo que me parece bastante revelador, por lo menos se empieza a reivindicar ya a estas alturas una literatura hispanoamericana con sus propios rasgos, debidos a experiencias comunes y distintas de las literaturas europeas y también de la española. A este concepto se une la idea de que las naciones hispanoamericanas se reúnan en un espíritu de solidaridad para contrarrestar la incomunicación manifiesta que existe entre ellas. En este sentido, vuelve a ser significativo que la obra se haya editado en París. Tanto a esta América poética como al proyecto de Torres Caicedo anteriormente presentado les ayuda de manera decisiva que la capital francesa fun- 
cione como plataforma para la distribución continental de la producción literaria hispanoamericana.

Ahora bien, la América poética de Cortés está organizada mucho más estrictamente que la de Gutiérrez, que había consistido en entregas sueltas a lo largo de los años 1846 y $1847 .{ }^{6}$ En el tomo de 1875 , los autores se ordenan según sus nacionalidades, concretamente las siguientes: figuran veintiún autores de Chile y se los coloca en primer lugar, supuestamente porque el compilador José Domingo Cortés provenía de este país. Siguen los respectivos apartados para Cuba (24), Perú (18), Bolivia (12), Ecuador (11), Argentina (24), Venezuela (12), Colombia (24), México (21), Uruguay (8) y Santo Domingo (19). Se excluye, por lo tanto, Brasil, y queda integrada Cuba a pesar de seguir siendo colonia española. Se combina la perspectiva continental con la nacional, que sigue siendo mantenida estrictamente sin que se intente organizar el material literario según pautas comunes para la literatura hispanoamericana. Y dentro de este criterio nacional, se sigue haciendo hincapié en las personalidades de los autores, cuyas obras vienen acompañadas de una noticia biográfica.

La práctica antológica del siglo XIX culmina en la América literaria de Francisco Lagomaggiore, editada en Buenos Aires en 1883 y en su segunda edición de 1890 . Se trata de una obra todavía más extensa que la América poética de Cortés, que incluye también obras en prosa. El prólogo alude de nuevo a la "falta de comunicación inte-

6 De hecho, Gutiérrez reinició el proyecto en 1865. El plan consistía en entregar un fascículo cada 15 días. El primero, junto a un fragmento de la "Alocución a la poesía" de Andrés Bello, contenía noticias críticas y muestras de la obra del P. Juan Bautista Aguirre, un poeta ecuatoriano del siglo XVIII, y de Juan Ruiz de Alarcón y Mendoza, el conocido dramaturgo áureo de México. Precede al segundo turno de esta "Colección escojida de composiciones en verso escrita por americanos en el presente siglo" (título que, desde luego, ya no es exacto, lo que a su vez demuestra los crecientes empeños historiográficos del proceso literario) un "prospecto", en el que se citan abundantes comentarios periodísticos a la primera edición. Valga como ejemplo la reseña en El Progreso de Valparaiso, en el que se alude a la perspectiva continental del proyecto: "Fuera de literaria, nosotros consideramos esta publicacion como un trabajo patriótico, de ese patriotismo sin reserva, que se alegra de las glorias de todas las naciones, como si fueran propias. Que orle al menos la vasta frente de Sud-América una sola corona de rosas, ya que su destino es dividirse y segregarse políticamente. Estos son los deseos que en nosotros despierta, y creemos que en muchos mas, la América Poética" (Prospecto de la $2^{\mathrm{a}}$ edicion: 3 ). 
lectual entre las repúblicas hispano-americanas" (Lagomaggiore 1883: V):

Este común aislamiento léjos de estrechar los vínculos que las atan [las repúblicas hispano-americanas, A.P.] en su pasado glorioso, cuando iniciaron la lucha heróica de la emancipacion, los afloja por el contrario, dándonos, como resultado inmediato, la secuestracion de estados que viven en un mismo continente; que fueron en un tiempo opulentas colonias de un mismo y poderoso soberano; que luego combatieron juntos por una misma causa; y que idénticos destinos deben cumplir en el tiempo y en el espacio.

Para remediar de alguna manera semejante estado de cosas, hemos afrontado la séria y penosa tarea de reunir en un haz las producciones de los hijos del norte y del sur de la América, presentando en un volúmen la prosa y el verso, -junto al inspirado cantor del Niágara el del Nido de Cóndores; al lado del de Mitre, el nombre respetado de Alaman. Así, en las páginas de este libro, aunque divididos por las fronteras artificiales que les hemos creado para metodizar nuestro trabajo, se confunden todos ellos en un solo terreno, y se cobijan bajo una sola enseña - la de la fraternidad intelectual (Lagomaggiore 1883: V).

Lagomaggiore reúne, como lo dice el subtítulo, "Producciones en prosa y verso", y mantiene como Cortés en su estructura el criterio nacional, pero calificándolo significativamente como "artificial". Dispone los textos en tres grandes secciones: "Sección política", "Sección literaria" y "Sección poética", incluyendo Argentina, Uruguay, Brasil, Chile, Perú, Bolivia, Colombia, Venezuela en la parte política; Argentina, Uruguay, Chile, Perú, Colombia, Venezuela y México en la literaria, y Argentina, Uruguay, Brasil, Chile, Perú, Bolivia, Ecuador, Colombia, Venezuela, México y Cuba en la parte poética, y, en cada una de las secciones una ulterior denominada "diversas nacionalidades". Cabe comentar, en primer lugar, la mera existencia de la "Sección política", la cual es debida a las estrechas relaciones y uniones personales entre el oficio político y literario que indica al hecho de que el concepto de "literatura" en estos momentos se encuentra todavía lejos de ser autónomo. Con respecto a los países considerados, llama la atención que se incluya Brasil en las partes sobre política y poética, lo que anteriormente no se pudo observar, llegando a una perspectiva continental verdaderamente abarcadora (y a pesar de hablar, en el prólogo, exclusivamente de las "repúblicas hispanoamericanas", Lagomaggiore 1883: V). 
Por lo demás, resulta interesante que no sólo consten autores decimonónicos sino también algunos de la época colonial como, por ejemplo, Sor Juana en el caso de México.

Señala la mayor independización del campo literario que Lagomaggiore prescinda en su segunda edición de 1890 de la "Sección política", siguiendo estructurando su obra según los estados nacionales con la subdivisión en cada caso entre "prosa" y "verso". Los nombres de los literatos incluidos no coinciden exactamente con la edición anterior, pero hay unos cuantos que se repiten.

El cambio más tajante en la obra -que ahora llega a abarcar dos tomos- consiste en el hecho de que para cada país se incluye un ensayo panorámico sobre su desarrollo literario, escrito en cada caso por un especialista nacional. Estos ensayos son en sí bastante heterogéneos, pero en algunos casos se nota claramente la tendencia de fortalecer una perspectiva histórica que llega a épocas pre-independistas. Así, en la América literaria de Lagomaggiore el proyecto antológico de recopilación y el historiográfico de ordenación finalmente se combinan.

La "Advertencia" de 1890 es la reproducción del texto ya incluido en la edición de 1883 y hace sobre todo hincapié en la mencionada innovación:

Con el fin de encerrar en sus páginas un verdadero trasunto de la vida literaria de las repúblicas hispano-americanas, creímos indispensable preceder cada seccion de una reseña histórica y crítica que condensara en breve espacio aquello que, con rarísimas excepciones, no lo ha sido hasta ahora en ninguna de ellas, pues carecen todas de una historia de su desenvolvimiento intelectual hasta el día presente, si bien es cierto que algunas poseen estimables y meritorios estudios consagrados á determinadas épocas. Estas reseñas las debemos á escritores de sus respectivas nacionalidades, y á ellos ofrecemos aquí públicamente las más sinceras muestras de gratitud (Lagomaggiore 1890: IV).

Enumero, para que el panorama llegue a ser completo, los países y la cantidad de autores incluidos en cada caso: Argentina (46), Uruguay (31), Bolivia (7), Perú (22), Chile (44) en el primer tomo; Ecuador (20), Colombia (51), Venezuela (39), Centro América (22), México (50), Cuba (41) en el segundo. Esta segunda edición, por lo tanto, ya no incluye al lusohablante Brasil. ${ }^{7}$

7 En algunos casos, se repiten autores en los dos apartados; sólo incluyo la totalidad de personas mencionadas. 
Tal vez venga a cuenta destacar que en comparación con el tomo anterior, el número de autores presentados para México ha aumentado bastante: en 1883 constaban tan sólo tres autores en la parte literaria y trece en la parte poética, para llegar a cincuenta en 1890. El hecho es sobre todo importante porque precisamente entre México y los países del Cono Sur, y, en primer lugar, Argentina, lugar de publicación de la antología de Lagomaggiore, parece ser extremadamente fuerte la observada incomunicación. Precisamente en el mismo año de 1890 sale en México la antología titulada Escritores y poetas sud-americanos a cargo de Francisco Sosa que apunta explícitamente a esta situación. Aquí, el adjetivo "sud-americano" es muy conscientemente elegido, ya que Sosa lamenta que no llegan a México obras de los países de la parte austral del subcontinente, y vice versa: "Corta como es la cifra de los capítulos aquí reunidos, representa, sin embargo, una labor que sólo podrán apreciar los que saben cuán difícil es adquirir en México obras sud-americanas" (Sosa 1890: 287).

Supongo que el comentario de la situación por parte del editor se debido a la guerra con Estados Unidos con la subsiguiente pérdida de territorios y a la invasión francesa en México:

Los vínculos que crean el origen, el idioma y la identidad de costumbres y de instituciones, no han bastado á cimentar entre las Repúblicas hispano-americanas relaciones por tal manera estrechas, que pueda decirse con justicia que existan fuertes lazos de unión, capaces de mancomunar en un momento dado los intereses de todas ellas, para conservar el predominio de la raza, y para dejar incólume su independencia é íntegro su territorio. Manifestaciones más ó menos ardientes, de simpatía, se han dejado escuchar en las grandes crisis, en los períodos de lucha; pero cuando la libertad ha peligrado, cuando enemigos exteriores han invadido algún pueblo hermano, éste ha debido sus triunfos á sus propios esfuerzos, pues se ha visto en total aislamiento, á pesar de que la pérdida de su autonomía habría significado no solamente un cambio de forma en su régimen interior, sino una amenaza para las demás Repúblicas del Continente (Sosa 1890: III-IV).

El objetivo de Sosa no es tanto demostrar características comunes en las obras de los distintos países hispanoamericanos, sino dar a conocerlas como condición previa para luego poder fomentar la "fraternidad de las Repúblicas hispano-americanas":

Porque así como en el trato humano ó social para estimarse los individuos necesitan conocerse profunda y no superficialmente, así para que 
los pueblos fraternicen, no basta la comunión de ideas, y la unidad de origen, idioma, costumbres é instituciones.

De ahí que, buscando un punto de partida para marcar nuevos derroteros á la opinión, para deshacer el hielo que nos separa, [...] hemos perseguido con tesón el establecimiento de relaciones literarias, el cange de obras, y cuanto pudiera contribuir á despertar, de un extremo á otro de la América latina, el deseo de conocer la historia y la literatura de cada una de las nacionalidades en ella constituídas. Después vendrán, como natural consecuencia, sin esfuerzo alguno, las relaciones oficiales ó diplomáticas; no de mera cortesía, sí como medio para estrechar sincera y cordialmente los lazos de unión que desde el primer tercio del siglo debieran haber existido (Sosa 1890: V-VI).

De hecho, este llamado a solidarizarse hace bastante falta teniendo en cuenta los numerosos conflictos bélicos existentes no sólo contra potencias extranjeras como Francia y los Estados Unidos, sino también entre las mismas naciones hispanoamericanas. Para Sosa, en todo caso, resulta primordial dar a conocer la literatura del Cono Sur en México, cosa por lo visto nada evidente en esos tiempos.

Sosa no presenta "obras sud-americanas" propiamente dichas, sino ensayos críticos a la manera de Torres Caicedo. La selección es mucho más reducida que la de Lagomaggiore (a quien se refiere y cita explícitamente), pero más o menos representativa con respecto a los cánones de la época: tenemos a cuatro peruanos (Ricardo Palma, Luis Benjamín Cisneros, Clorinda Matto de Turner, José Antonio de Lavalle), siete argentinos (Bartolomé Mitre, Juana Manuela Gorriti, Carlos Guido y Spano, Ricardo Gutiérrez, Mariano A. Pelliza, Rafael Obligado, Adolfo P. Carranza), dos chilenos (Guillermo Matta, Eduardo de la Barra), un ecuatoriano (Numo Pompilio Llona), un uruguayo (Juan Zorrilla de San Martín), un venezolano (Nicanor Bolet Peraza), y un colombiano (Jorge Isaacs). Son, efectivamente, en la mayoría los autores canónicos hasta hoy en día. Además, vale la pena resaltar que Sosa es el primero de todos los antologistas que incluye a Clorinda Matto de Turner.

En su intento de llegar a establecer un mayor vínculo cultural con el continente sud-americano, Sosa remite también a Menéndez Pelayo y al creciente interés que la literatura hispanoamericana está despertando en España:

El interés cada día mayor con que en España misma, se ven los estudios relativos á la literatura del nuevo continente, presagia una nueva éra. Dos académicos á quienes hemos citado en las páginas que preceden, los 
Sres. Valera y Barrantes, el primero en sus amenas y deleitosas Cartas Americanas y el segundo en sus artículos bibliográficos publicados en la España Moderna, siguen paso á paso el desenvolvimiento intelectual de las repúblicas latino americanas, al propio tiempo que el erudito $\mathrm{Me}$ néndez Pelayo acoge con vivo interés cuantos libros y noticias le proporcionan sus admiradores y sus amigos de este lado del Atlántico; libros y noticias que al eminente crítico le sirven no pocas veces para rectificar los juicios que le sugirieran en otros días los datos por extremo incompletos que entonces poseía (Sosa 1890: 288).

La Antología de poetas hispano-americanos (1893) y la Historia de la poesía hispano-americana (Madrid, 2 tomos, 1911/13) de Menéndez Pelayo dan efectivamente paso a la consideración de la literatura hispanoamericana a nivel mundial. En qué medida estas obran suponen una "entrada oficial en el tesoro de la literatura española, al cual hace mucho tiempo que debieran estar incorporadas", como lo manifiesta el mismo Menéndez Pelayo (Menéndez Pelayo [1913]: 11), ha sido desde luego cuestionado. El problema consiste en la idea de incorporar la literatura hispanoamericana en el conjunto de la española sin rescatar sus particularidades. Por otro lado, no queda duda de que la obra de Menéndez Pelayo certifique por lo menos el creciente interés hacia la producción literaria del otro lado del Atlántico, consagrada paralelamente por el reconocimiento que obtiene a nivel universal la corriente modernista. En este sentido, es importante la nueva repartición de poderes en los años subsiguientes: la creciente hegemonía estadounidense motiva un nuevo tipo de solidaridad entre España y los países hispanoamericanos y le concede una nueva dimensión al registro de la latinidad. ${ }^{8}$

Con Menéndez Pelayo estamos frente a la perspectiva exterior sobre la literatura del subcontinente hispanoamericano. De ahí que no

8 De todas formas, Menéndez Pelayo no incluye todavía al personaje emblemático de Rubén Darío en sus obras, a pesar de que una de sus obras de referencia, que era precisamente la América Literaria de Lagomaggiore, sí lo hace. Tan sólo le dedica a Darío una breve alusión profética en el primer tomo de su Historia de la poesía hispano-americana: "Una nueva generación literaria ha aparecido en la América Central, y uno por lo menos de sus poetas ha mostrado serlo de verdad." La afirmación va acompañada de una nota a pie de página: "Claro que se alude al nicaragüense D. Rubén Darío, cuya estrella poética comenzaba a levantarse en el horizonte cuando se hizo la primera edición de esta obra en 1892. De su copiosa producción, de sus innovaciones métricas y del influjo que hoy ejerce en la juventud intelectual de todos los países de lengua castellana, mucho tendrá que escribir el futuro historiador de nuestra lírica" (Menéndez Pelayo 1948, I: 206). 
extrañe que Menéndez Pelayo utilice, al contrario de las restantes antologías citadas, el rótulo de "hispanoamericano" en vez del simplemente "americano". Así se explica también la denominación "Lettres hispano-américaines" de una sección incluida, a partir de 1890, en la importante revista parisina Le Mercure de France (Carter 1968: 1920). La especificación se debe, pues, claramente a la perspectiva exterior, tanto española como francesa, aun cuando la aludida sección del Mercure de France ha sido dirigida siempre por hispanoamericanos.

Lo mismo se puede suponer para las primeras historias literarias continentales propiamente dichas, que se realizan igualmente desde fuera del subcontinente hispanoamericano y por autores extranjeros. Las dos primeras historias literarias continentales se realizan en los Estados Unidos y en Alemania: The Literary History of Spanish America (1916) de Alfred Coester y Die Spanisch-Amerikanische Literatur in ihren Hauptströmungen (1924) de Max-Leopold Wagner. Al contrario de Coester, quien mantiene la subdivisión según nacionalidades, la obra de Wagner adopta por primera vez un enfoque integrador, marcando así que su finalidad consiste en esbozar "lo común de un desarrollo general", "das Gemeinsame einer Gesamtentwicklung" (Wagner 1924: IV). Por lo demás, ambos trabajos se sitúan muy obviamente en la línea de Menéndez Pelayo, es lo que más lamentan las voces que empiezan a plantearse la cuestión de la existencia de una literatura continental hispanoamericana "desde dentro" que apunte hacia una psicología común más allá del compartido pasado político y del color local, hacia un "alma común", como lo expresa Rufino Blanco Fombona. ${ }^{9}$

9 Rufino Blanco Fombona utiliza esta expresión en 1908: "La América Latina, poblada antes del descubrimiento por razas indígenas muy semejantes; sometida y colonizada por el mismo conquistador: campo de un extremo a otro de las mismas emigraciones europeas, posee hoy, aunque dividida en diferentes Repúblicas, un alma común. De ahí que haya una literatura iberoamericana; y que el escritor de Guatemala parezca al de Chile o al de Bolivia. [...] [L]os Iberoamericanos, respecto a constitución mental, distamos cien leguas de los españoles. Nosotros somos un pueblo eminentemente revolucionario; corremos hacia la Ciencia; vemos hacia adelante, hacia el Porvenir, desgarramos el velo del Futuro. La psicología de España es muy otro" (Blanco Fombona, en Kristal 1994: 198). Debo la cita a Efraín Kristal, quien demostró en qué sentido "la historia de la literatura hispanoamericana es fenómeno reciente" (Kristal 1994: 195). 
Pero hay también otras voces. El colombiano Baldomero Sanín Cano por ejemplo, quien también se plantea la pregunta si "existe una literatura hispanoamericana", la niega polémicamente por la manifiesta heterogeneidad de las distintas regiones y por el aislamiento mutuo: "[A] causa de la incomunicación en que vivimos, las diferencias espirituales entre unos pueblos y otros se tornan cada vez más significantes" (Sanín Cano 1989: 73). Estas palabras, enunciadas alrededor de los años veinte del siglo pasado, se relativizan a mi modo de ver en la medida en que son, ante todo, una reacción a la perspectiva globalizadora que viene desde fuera. Sanín Cano menciona explícitamente a Coester y dice que "[e]s de lamentar que la primera tentativa de historia literaria hispanoamericana se deba a un extranjero" (Sanín Cano 1989: 72). Además, llega a constatar que

[e]1 lazo común de estos pueblos no es en rigor el idioma sino el viaje a Europa, la caravansera de París. Es en el Viejo Mundo donde los hispanoamericanos descubrimos el lazo que nos une espiritualmente (Sanín Cano 1989: 73),

pero a la vez se demuestra consciente que tampoco este vínculo parisino, por ser un fenómeno pasajero y de elite, puede fundar ese fondo espiritual común.

Por provocadoras y contradictorias que sean estas afirmaciones, demuestran claramente el cambio de paradigma que se efectúa a principios del siglo XX: la pregunta de una particularidad de la literatura hispanoamericana que transgreda el mero costumbrismo y la compartida experiencia política de la Independencia se plantea explícitamente y encuentra, como ha demostrado Efraín Kristal, su mayor exponente en Pedro Henríquez Ureña, quien en sus Seis ensayos en busca de nuestra expresión (1928) desarrolla el concepto de "un espíritu o una psicología hispanoamericana transnacional" (Kristal 1994: 199).

Así no cabe duda de que en el pasado siglo XX, la noción de literatura hispanoamericana se diversificó y se llenó de significados mucho más sustanciales que las meras opciones pragmáticas que dominan muchas veces las antologías decimonónicas. Sin embargo, creo que aquéllas forman una sólida base para las discusiones "desde dentro" acerca de la existencia de una historia e historia literaria hispanoamericanas, a más de que algunos de los aspectos destacados, en 
particular el rol que adquiere la perspectiva exterior, sea parisina, estadounidense o española, demuestran una longevidad impresionante. ${ }^{10}$

Resumimos lo observado a lo largo de las precedentes páginas retomando las distintas nomenclaturas que se encuentran en las antologías discutidas: "americano" se utiliza dentro del subcontinente latinoamericano para denotar una vista global de la creación literaria de las naciones independizadas del Imperio español (y, a veces, portugués), mientras que "hispanoamericano" se utiliza básicamente desde fuera de América Latina, para hacer hincapié en el lenguaje y, sobre todo, porque "americano" ha llegado muy rápidamente a tomarse como sinónimo de "estadounidense". "Latinoamericano", aun cuando hoy en día se suele tomar como denominación común de los países hispanoamericanos y de Brasil, en el siglo XIX y a principios del XX conlleva un fuerte aspecto ideológico debido al contexto del concepto de la latinité, desde el punto de vista francés primero, y, posteriormente, de la "raza latina" que vuelve a incluir a España en un movimiento de distanciamiento de los Estados Unidos. "Sudamericano" se lee un poco menos y en un primer momento parece ser también una construcción auxiliar para denominar las zonas independizadas de España y Portugal. Sin embargo, en un momento determinado adquiere otro significado más, a saber la diferenciación de las regiones del Cono Sur del norteamericano México. A mi modo de ver, esto se debe al hecho de que los dos centros con los campos literarios más desarrollados, México y Argentina, se encuentran en los dos extremos del espacio latinoamericano.

$\mathrm{Y}$ con respecto a la perspectiva histórica de una historia literaria hispanoamericana, que en el siglo XX va a llegar al primer plano de la discusión, cabe rescatar que las antologías continentales se limitan, salvo pocas excepciones, a autores de la época post-independentista, afirmando el discurso progresista de las naciones independizadas. Las

10 La observación vuelve a ser afirmada por Boyd C. Carter en 1968: "Considerando lo que ha sido, tradicionalmente, el aislamiento cultural de Hispanoamérica, exceptuando el movimiento modernista y el vanguardismo del tercer decenio del siglo, no hay motivo para admirarse de que el concepto de la unidad cultural de Hispanoamérica, se haya definido y concebido a veces con mayor claridad en las revistas publicadas por hispanoamericanos en el extranjero, especialmente en París, de lo que habría sido posible en sus respectivos países" (Carter 1968: 19). Evidentemente, el tema adquiere nueva relevancia con el boom al que Carter todavía no considera. 
antologías todavía no ponen en primer plano la perspectiva histórica; presentan, no periodizan por épocas ni buscan orígenes. Su único criterio, sean recopilaciones de creación literaria o colecciones de ensayos, es la persona autorial, su único criterio de estructuración el nacional. Pero, como hemos visto, desembocan en la historiografía, cuando Lagomaggiore incluye la dimensión histórica en la edición de 1890 de su América literaria.

En alguna medida, las antologías anteriores, por lo menos las que no se reducen a la poesía, también integran implícitamente esta dimensión cuando incluyen, a través de los autores que muchas veces son más bien políticos o científicos que literatos, el ensayo histórico. Así, abren el camino para incluir la historia en la historiografía literaria, como ha demostrado recientemente Katja Carrillo Zeiter (2011).

Queda obvio que las antologías continentales decimonónicas no indagan explícitamente en una perspectiva ideológica de la psicología nacional y tienen bastante poco potencial metadiscursivo. Optan por llevar a cabo una completa presentación de la creación literaria para dar prueba de su mera existencia. Sin embargo, proporcionan el material para la posterior ordenación y revisión del proceso literario y ofrecen, si bien implícitamente, sus propias propuestas acerca de las vías que va a emprender la literatura "latino-/hispano-/sud-americana". De este modo, la perspectiva continental llegó a respaldar una noción "americanista" más allá de las diferencias nacionales que finalmente pudo desembocar en el auto-análisis de la conciencia latinoamericana.

\section{Bibliografía}

Achugar, Hugo (1997): "Parnasos fundacionales. Letra, nación y Estado en el siglo XIX". En: Revista Iberoamericana, 63, 178-179, pp. 13-31.

Campra, Rosalba (1987): "Las antologías hispanoamericanas del siglo XIX. Proyecto literario y proyecto político". En: Casa de las Américas, 26, 162, pp. 37-46.

Carilla, Emilio (1990): “José María Torres Caicedo y la literatura argentina". En: Alba de América, 6, 14-15, pp. 59-74.

Carrillo Zeiter, Katja (2011): Die Erfindung einer Nationalliteratur. Literaturgeschichten Argentiniens und Chiles (1860-1920). Frankfurt am Main: Vervuert.

Carter, Boyd C. (1968): Historia de la literatura hispanoamericana a través de sus revistas. México, D.F.: De Andrea.

Coester, Alfred (1916): The Literary History of Spanish America. New York: The Macmillan Company. 
Cortés, José Domingo (1875): América poética. Poesías selectas americanas. Paris/México, D.F.: Librería de A. Bouret é Hijo.

Figueroa, Pedro Pablo (1907): Dos perlas literarias americanas. Memorias de un botón de Rosa. Soledad. Novelas americanas por Bartolomé Mitre. Precedidas de un prólogo de Pedro Pablo Figueroa. Buenos Aires: Kraft.

González Echevarría, Roberto (1994): "Álbumes, ramilletes, parnasos, liras y guirnaldas: fundadores de la historia literaria latinoamericana”. En: Ortega, Julio/Amor y Vázquez, José (eds.): Conquista y contraconquista: la escritura del nuevo mundo. México, D.F./Providence: El Colegio de México/Brown University, pp. 489-503. (Actas del XXVIII Congreso del Instituto Internacional de Literatura Iberoamericana.)

González-Stephan, Beatriz (2002): Fundaciones: canon, historia y cultura nacional. La historiografia literaria del liberalismo hispanoamericano del siglo XIX. Madrid/Frankfurt am Main: Iberoamericana/Vervuert.

Gutiérrez, Juan María (1846-1847): América poética. Colección escogida de composiciones en verso escritas por americanos en el presente siglo. Valparaíso: Imprenta del Mercurio.

- (aprox. 1865): "Prospecto de la $2^{\mathrm{a}}$ edición". En: Gutiérrez, Juan María (ed.): América poética. Colección escogida de composiciones en verso escritas por americanos en el presente siglo. Valparaíso: Teodomiro Real y Prado, pp. 1-3.

Gutiérrez, Juan María/Ticknor, Jorge (1867): “Correspondencia Literaria”. En: Revista de Buenos Aires, 12, pp. 563-567.

Henríquez Ureña, Pedro (1928): “Caminos de nuestra historia literaria”. En: Henríquez Ureña, Pedro: Seis ensayos en busca de nuestra expresión. Buenos Aires: Babel, pp. 37-51.

Kristal, Efraín (1994): "En torno a la historia del concepto de historia literaria hispanoamericana". En: Aullón de Haro, Pedro (ed.): Teoría de la historia de la literatura y el arte. Madrid: Verbum, pp. 195-209.

Lagomaggiore, Francisco (1883): América literaria. Producciones selectas en prosa y verso coleccionadas y editadas por Francisco Lagomaggiore. Buenos Aires: Imprenta de "La Nación".

- (1890): América literaria. Producciones selectas en prosa y verso. Coleccionadas y editadas por Francisco Lagomaggiore. Segunda edición notablemente aumentada. Buenos Aires: Imprenta de "La Nación".

Menéndez Pelayo, Marcelino (1893): Antología de poetas hispano-americanos. Madrid: Sucesores de Rivadeneyra.

- ([1911/1913] 1948): Historia de la poesía hispano-americana. 2 tomos. Santander: Aldus.

Mitre, Bartolomé ([1847] 1928): Soledad. Buenos Aires: Imprenta de la Universidad.

Paatz, Annette (2001): "Aspekte medialen Kulturtransfers im 19. Jahrhundert: zur Positionierung der Revue des Deux Mondes im kulturellen Feld Lateinamerikas". En: Engelbert, Manfred/Pohl, Burkhard/Schöning, Udo (eds.): Märkte, Medien, Vermittler. Fallstudien zur interkulturellen Vernetzung von Literatur und Film. Göttingen: Wallstein, pp. 145-186. 
Paatz, Annette (2012): "Paris et les débuts de l'histoire littéraire hispano-américaine". En: Gengembre, Gérard/Meier, Franziska/Wild, Francine (eds.): Écrire, ou la présence du passé. Actes de deux colloques tenus à l'Université de Caen et à l'Université de Göttingen. Caen: Presses Universitaires de Caen.

Quesada, Vicente (1864): "Reseña de José María Torres Caicedo, Ensayos biográficos y de crítica literaria". En: Revista de Buenos Aires, II, 5, pp. 145-156.

Sanín Cano, Baldomero (1989): “Existe una literatura hispanoamericana?”. En: Sanín Cano, Baldomero: El oficio de lector. Caracas: Biblioteca Ayacucho, pp. 71-75.

Sosa, Francisco (1890): Escritores y poetas sud-americanos. México, D.F.: Oficina Tip. de la Secretaría de Fomento.

Torres Caicedo, José María (1863): Ensayos biográficos y de crítica literaria sobre los principales poetas y literatos hispano-americanos. 2 tomos. Paris: Guillaumin.

- (1868): Ensayos biográficos y de crítica literaria sobre los principales publicistas, historiadores, poetas y literatos de la América Latina. Paris: Baudry, Librería Europea.

Wagner, Max Leopold (1924): Die Spanisch-Amerikanische Literatur in ihren Hauptströmungen. Leipzig/Berlin: Teubern. 